\title{
Phase Stability in Thermally-Aged CASS CF8 under Heavy Ion Irradiation
}

\author{
Meimei Li ${ }^{1}$, Michael K. Miller ${ }^{2}$, Wei-Ying Chen ${ }^{1}$ \\ ${ }^{1}$ Argonne National Laboratory, 9700 S. Cass Avenue, Argonne, IL 60439 \\ ${ }^{2}$ Oak Ridge National Laboratory, P.O. Box 2008, Oak Ridge, TN 37831
}

\begin{abstract}
The stability of the microstructure of a cast austenitic stainless steel (CASS), before and after heavy ion irradiation, was investigated by atom probe tomography (APT). A CF8 ferriteaustenite duplex alloy was thermally aged at $400{ }^{\circ} \mathrm{C}$ for $10,000 \mathrm{~h}$. After this treatment, APT revealed nanometer-sized G-phase precipitates and Fe-rich $\alpha$ and Cr-enriched $\alpha^{\prime}$ phase separated regions in the ferrite. The thermally-aged CF8 specimen was irradiated with $1 \mathrm{MeV} \mathrm{Kr}$ ions to a fluence of $1.88 \times 10^{19}$ ions $/ \mathrm{m}^{2}$ at $400{ }^{\circ} \mathrm{C}$. After irradiation, APT analysis revealed a strong spatial/dose dependence of the G-phase precipitates and the $\alpha-\alpha^{\prime}$ spinodal decomposition in the ferrite. For the G-phase precipitates, the number density increased and the mean size decreased with increasing dose, and the particle size distribution changed considerably under irradiation. The inverse coarsening process can be described by recoil resolution. The amplitude of the $\alpha-\alpha^{\prime}$ spinodal decomposition in the ferrite was apparently reduced after heavy ion irradiation.
\end{abstract}

Keywords: CASS, G-phase precipitates, spinodal decomposition, heavy ion irradiation, APT

\section{INTRODUCTION}

Cast austenitic stainless steels (CASSs) are used in light water reactors (LWRs) for components with complex shapes, e.g., pump casings, valve bodies, elbows, control rod guide tube spaces, etc. CASSs in LWR core internals can experience hardening and embrittlement due 
to extended exposures to elevated temperatures and/or neutron irradiations [1-5]. Previous studies have shown that thermal aging increased the yield and tensile strength, and decreased the ductility, impact energy and fracture toughness of CASS materials [1-4]. A recent study suggests that a combination of thermal aging and irradiation may further reduce the fracture resistance of CASS alloys [5]. A potential interaction between the two degradation processes of irradiation damage and thermal aging needs to be evaluated for the long-term service of CASS components.

CASS alloys have an austenite - ferrite duplex microstructure. A small amount of $\delta$ ferrite is formed together with austenite in the solidification process. The ferrite phase is critical for both the mechanical properties and corrosion resistance of CASS alloys. However, the ferrite is susceptible to embrittlement during thermal aging. The mechanisms of thermal aging embrittlement of CASSs have been studied extensively [3-17]. It is suggested that thermal aging embrittlement at $300-500^{\circ} \mathrm{C}$ are associated with several microstructural processes in the ferrite phase: (1) the formation of Cr-enriched $\alpha^{\prime}$ phase through spinodal decomposition, (2) precipitation of G-phase $\left(\mathrm{M}_{6} \mathrm{Ni}_{16} \mathrm{Si}_{7}, \mathrm{M}=\mathrm{Mn}, \mathrm{Cr}\right)$, and (3) the precipitation of carbides at the austenite-ferrite phase boundaries.

Irradiation-induced embrittlement in CASS materials is much less understood. Irradiation introduces a large population of point defects and point-defect complexes in crystalline solids. Further evolution of these defects leads to formation of extended defect structures, such as dislocation loops, dislocation networks, and voids, giving rise to irradiation hardening and embrittlement [18]. Furthermore, the presence of non-equilibrium point defects in an irradiated material can interact with the microstructure in various ways, significantly affecting the stability of microstructural phases. Previous studies have reported different findings of the effect of 
irradiation on spinodal decomposition in Fe-Cr alloy systems. Miller et al. observed enhanced spinodal decomposition in a neutron-irradiated Fe-32\%Cr model alloy irradiated to 0.03 dpa at $290^{\circ} \mathrm{C}$ [17]. Fujii and Fukuya [19] however, reported the reduced spinodal decomposition in CF8M irradiated with $6.4 \mathrm{MeV}$ Fe ions at $300^{\circ} \mathrm{C}$. While a complete understanding of the effect of irradiation on spinodal decomposition in ferrite is still largely needed, almost no studies have been reported in the literature on G-phase evolution under irradiation in CASS alloys. When an alloy containing second-phase precipitates is subjected to irradiation, a number of processes can take place simultaneously, e.g., recoil resolution of atoms from precipitates, irradiation disordering or amorphorization, irradiation-enhanced diffusion, and irradiation-induced solute segregation [20]. Precipitates can be restructured, or dissolved, and coarsening can either be enhanced or reversed [20]. Phase stability under irradiation is not only a complex scientific problem but also has a profound impact on the applications of engineering alloys in nuclear reactor environments.

The present research investigates the dose dependence of G-phase precipitation and spinodal decomposition in the ferrite phase of a thermally-aged CF8. The study takes advantage of the spatial variations of displacement damage and $\mathrm{Kr}$ ion deposition in an ion-irradiated specimen, and the spatial resolution of atom probe tomography (APT) [21] to obtain the dosedependent data in a single ion-irradiated specimen. A thermally-aged CF8 was irradiated with 1 $\mathrm{MeV} \mathrm{Kr}$ ions and subsequently analyzed by APT along the ion irradiation direction. This is a companion study of in situ ion irradiation with transmission electron microscopy (TEM) [22] to understand the kinetic process of defect evolution and second-phase precipitation under irradiation and the combined effects of thermal aging and irradiation in CF8. 


\section{EXPERIMENTAL PROCEDURE}

The material examined was a cast CF8 austenitic stainless steel. The chemical composition (wt\%) of CF8 was Fe-20.46Cr-8.08Ni-0.64Mn-0.31Mo-1.07Si-0.063C-0.062N0.021P-0.014S. The ferrite - austenite duplex structure of CF8 is shown in Fig. 1. The composition of the ferrite was 65.67Fe-26.37Cr-4.46Ni-2.35Si-0.56Mn-0.25Mo-0.01P (at\%) or 67.45Fe-25.22Cr-4.82Ni-1.21Si-0.56Mn-0.45Mo-0.01P (wt\%). Metallographic measurement estimated that the ferrite content was $\sim 19 \%$. The material was aged at $400^{\circ} \mathrm{C}$ for $10,000 \mathrm{~h}$ prior to ion irradiation to simulate the thermal aging effect for the end-of-life rector service.

Disc specimens of $3 \mathrm{~mm}$ in diameter and $\sim 100 \mu \mathrm{m}$ in thickness were irradiated with 1 $\mathrm{MeV} \mathrm{Kr}$ ions in an electron microscope at the IVEM-Tandem Facility, Argonne National Laboratory. Ion irradiation was conducted at $400^{\circ} \mathrm{C}$ to a fluence of $1.88 \times 10^{19} \mathrm{ions} / \mathrm{m}^{2}$ at a flux of $6.25 \times 10^{15} \mathrm{ions} / \mathrm{m}^{2} / \mathrm{sec}$. The ion flux was measured by a Faraday cup located at $2 \mathrm{~cm}$ from the specimen in the microscope. The irradiation temperature was controlled within $\pm 3{ }^{\circ} \mathrm{C}$. The dpa values were estimated using the damage rate obtained from SRIM calculations based on the Kinchin-Pease formalism [23]. The SRIM calculation was performed for pure iron and the displacement energy of $40 \mathrm{eV}$ and density of $7.8 \mathrm{~g} / \mathrm{cm}^{3}$ with $1 \mathrm{MeV} \mathrm{Kr}$ ions. The calculated depth profile of the atomic displacements and $\mathrm{Kr}$ ion distribution in pure iron is given in Fig. 2. The dpa values were estimated by:

$$
\mathrm{dpa}=\frac{\Phi \times 10^{8} \times \text { damage }- \text { rate }}{N},
$$

where $\Phi$ is the ion fluence in ions $/ \mathrm{cm}^{2}$, the damage rate in vacancies/ion $/ \AA$, and $N$ the atomic number density in atoms $/ \mathrm{cm}^{3}$. 
APT specimens were prepared from site specific locations in the $\delta$-ferrite with a FEI Nova 200 dual beam FIB [24-27]. The FIB lift-out sample was removed from the surface of the ion-irradiated side and in the direction normal to the surface of a disk specimen. Details of the specimen fabrication process of ion-irradiated specimens can be found in [26]. The APT data were collected with a CAMECA Instruments Inc. LEAP 4000X HR local electrode atom probe. The data was acquired in laser-pulsed mode at a specimen base temperature of $30 \mathrm{~K}$. Shortduration, ultraviolet (UV) laser pulses with a laser energy of $100 \mathrm{pJ}$ were focused on the apex region of the needle-shaped specimen to field evaporate the surface ions at a pulse repetition frequency of $200 \mathrm{kHz}$. Data reconstruction and analysis were performed with the CAMECA Instruments Inc. Integrated Visualization and Analysis Software (IVAS ${ }^{\circledR}$ 3.6.6) [26]. The average effective radii of the G-phase precipitates were estimated from the averages of the volumes defined by a $10 \%\left({ }^{60,61,62,64} \mathrm{Ni}+\mathrm{Si}\right)$ concentration iso-surface assuming a spherical geometry, i.e., $r_{e f f}=\sqrt[3]{3 V / 4 \pi}$. The number densities were estimated from the number of fully-contained plus $50 \%$ of the partially-contained precipitates within the volume, the number of ions in the assigned peaks of the mass spectra with the peak deconvolution procedure, ignoring Ga and the hydrogen peaks, taking into account the detection efficiency of the time-of-flight mass spectrometer, 37\%, and the volume of the standard 2 atom body center cubic (bcc) unit cell of Fe [21]. The extent of the $\alpha-\alpha^{\prime}$ phase separation was estimated with a method based on the Larger, Bar-on, Miller (LBM) model [21,27]. The depth-dependent dose through the specimen thickness was determined by correlating the APT-measured distribution profile of implanted $\mathrm{Kr}$ ions and the SRIM-calculated Kr distribution profile (shown in Fig. 2). It should be noted that two specimens in the identical aging and irradiation condition were analyzed, and the results were consistent between the two specimens. 


\section{RESULTS}

\subsection{G-phase precipitation}

APT analysis revealed nanoscale G-phase precipitates induced by thermal aging and ion irradiation in CF8, which were confirmed by TEM in a companion study [22]. A 10 at. \% Ni+Si concentration isosurface of the ferrite phase in CF8 thermally aged at $400^{\circ} \mathrm{C}$ for $10,000 \mathrm{~h}$ is shown in Fig. 3(a). The size and morphology of G-phase precipitates are clearly illustrated in the concentration isosurface. Nanoscale spheroidal particles are uniformly distributed in the ferrite matrix.

The size distribution of the G-phase precipitates was measured and is given in Fig. 3(b) in the form of a histogram with the bin size of $0.5 \mathrm{~nm}$. The G-phase precipitates showed a broad size range with the dominant fraction at 4-6 nm. The average size and number density of Gphase precipitates were $4.8 \pm 1.2 \mathrm{~nm}$ and $9.7 \times 10^{22} / \mathrm{m}^{3}$, respectively in the thermally-aged CF8

A 10 at. \% Ni+Si concentration isosurface of the ferrite phase in the thermally aged CF8 that was irradiated to $1.88 \times 10^{19}$ ions $/ \mathrm{m}^{2}$ at $400^{\circ} \mathrm{C}$ is shown in Fig. 4 . To determine the distance of the starting point measured by APT from the ion-irradiated surface, the $\mathrm{Kr}$ ion distribution profile measured by APT was compared with that calculated by SRIM. The comparison, shown in Fig. 5, implies that the surface measured by APT was $120 \mathrm{~nm}$ from the ion-irradiated surface. The dose distribution along the APT analysis axis (or the specimen depth) can therefore be estimated. As shown in Fig. 4, the number density and size of the G-phase precipitates have a strong dependence on the distance from the ion-irradiated surface, and therefore, dose dependence. The density and size data of G-phase precipitates were analyzed with $50 \mathrm{~nm}$ thick slices, and are given in Fig. 6(a) as a function of the distance from the ion irradiation surface, and Fig. 6(b) as a function of corresponding irradiation dose, respectively. The number density of G- 
phase precipitates increased significantly with increasing dose, whereas the mean size decreased with increasing dose. The density change exhibited a two-slope behavior, with a slower increasing rate below $\sim 3 \mathrm{dpa}$, and a faster rate above $\sim 3 \mathrm{dpa}$.

The size distribution of G-phase precipitates in each $50 \mathrm{~nm}$ slice along the specimen depth is shown in Fig. 7. The distance given in Fig. 7 is consistent with that shown in Fig. 4 where the distance of $0 \mathrm{~nm}$ is $\sim 120 \mathrm{~nm}$ below the irradiation surface. The corresponding dose value was also included in Fig. 7. Irradiation has a strong effect on the size distribution of Gphase precipitates. A large fraction of G-phase particles was within the size range of 4-6 with the peak size of $\sim 5 \mathrm{~nm}$ at $\sim 0.03 \mathrm{dpa}$, similar to that in the thermally aged, i.e., unirradiated, CF8 data shown in Fig. 3(b). As the dose increased, G-phase particles became smaller and started to show a bimodal size distribution. A clear bimodal size distribution was observed in the dose range of 1-3 dpa. The bimodal size distribution gradually diminished as the dose continued to increase. At the peak dose of 3.82 dpa, the majority of G-phase particles was in $1.5-3.5 \mathrm{~nm}$ range with a peak size of $2.7 \mathrm{~nm}$.

\subsection{Spinodal decomposition}

Phase separation of the $\delta$-ferrite into Fe-rich $\alpha$ and Cr-enriched $\alpha^{\prime}$ regions by spinodal decomposition was also revealed by APT in the thermally-aged and irradiated CF8. The $\alpha^{\prime}$ phase exhibited a fully-interconnected structure, as shown in Fig. 8. Analysis of the $\alpha$ and $\alpha^{\prime}$ phases was performed based on the Langer, Bar-on, Miller (LBM) model [28]. The model fits 2 Gaussian distributions to the $\mathrm{Cr}$ concentration frequency distribution with one Gaussian centered at $\mu 1$, and the other at $\mu 2$ for the $\alpha$ and $\alpha^{\prime}$ phases, respectively. The best fit was the obtained by varying $\mu 1, \mu 2$ and the volume fraction with a maximum likelihood method [21,27]. The $\mathrm{Cr}$ 
distribution was calculated using a block size of 100 ions. The estimated $\mu 2$ values of the $\alpha^{\prime}$ phase as a function of distance/dose along the analysis axis for the aged CF8 irradiated to $1.88 \times 10^{19}$ ions $/ \mathrm{m}^{2}$ at $400^{\circ} \mathrm{C}$ is shown in Fig. 9. There is a trend of decreasing Cr concentration with increasing irradiation dose, implying reduced phase amplitudes, or degree of phase separation, after irradiation. A two-stage behavior was observed, with a slower decrease of $\mathrm{Cr}$ composition at doses $<1 \mathrm{dpa}$, and a faster drop at doses $>1 \mathrm{dpa}$. The $\chi^{2}$ values were generally lower in the high-dose region than in the low-dose region.

\section{DISCUSSION}

Thermal aging at $400^{\circ} \mathrm{C}$ for $10,000 \mathrm{~h}$ introduced a high number density of G-phase precipitates in the ferrite matrix in CF8. When the thermally-aged CF8 was subjected to irradiation with $1 \mathrm{MeV} \mathrm{Kr}$ ions at $400^{\circ} \mathrm{C}$, the number density of G-phase precipitates increased and the mean size decreased with increasing dose. The initial binominal distribution of G-phase precipitates in the aged specimen gradually shifted towards a bimodal distribution at doses of 1-3 dpa. The bimodal size distribution diminished at higher doses with an overall smaller mean size of G-phase particles. It is apparent that there was an inverse coarsening process occurred under irradiation in the thermally-aged CF8.

The inverse coarsening behavior in CF8 may be understood by recoil resolution. Frost and Russell [29] obtained inverse coarsening rates based on the following physical processes: radiation-induced ejection of solute atoms from the particles into the matrix, and diffusion of this solute back to or away from the particle. The inverse coarsening process can be described by:

$$
\frac{d r}{d t}=\left(1-\frac{r}{r_{m}}\right) \frac{1}{r^{2}} \frac{L}{(L-r)} \frac{S R^{3}}{48},
$$


where $r$ is the particle radius, $r_{m}$ is the particle radius at which there is no flux to or away from a particle, $L$ is a half of inter-particle spacing, $S$ is the damage rate, and $R$ is the recoil distance. The evolution of $r$ with time $t$ can be estimated for three different particle size regimes:

$$
\begin{array}{lll}
r<<r_{m}, & \frac{r(t)^{3}}{r(0)^{3}}=1+\frac{t}{\tau_{A}} \quad \text { where } \tau_{A}=\frac{48 r(0)^{3}}{S R^{3}} \\
r>>r_{m}, & \frac{r(t)^{2}}{r(0)^{2}}=1-\frac{t}{\tau_{B}} \quad \text { where } \tau_{B}=\frac{24 r_{m} r(0)^{2}}{S R^{3}} \\
r \approx r_{m}, & r(t)=r_{m}+\left(r(0)-r_{m}\right) \exp \left(-\frac{t}{\tau_{C}}\right) \text { where } \tau_{C}=\frac{48 r_{m}^{3}}{S R^{3}}
\end{array}
$$

As shown in Fig. 10, the evolution of the mean size of G-phase precipitates with dose/time can be well described by the Frost-Russell model, i.e.:

$$
r(S t)=1.3+0.875 * \exp \left(-\frac{S t}{0.74}\right)
$$

with $r_{m}=1.3 \mathrm{~nm}, R=5.3 \mathrm{~nm}$ at $S=0.001 \mathrm{dpa} / \mathrm{s}$. The good agreement between the experiment and model also implies that the evolution of the particle size is insensitive to the dose rate under irradiation.

The characteristic diffusion distance, $(D t)^{1 / 2}$ can be estimated using the steady-state model by Frost and Russell [29]:

$$
\sqrt{D t} \approx L \sqrt{L / r}
$$

where $D$ is the diffusion coefficient. At the peak dose of $3.82 \mathrm{dpa},(D t)^{1 / 2} \approx 9 \mathrm{~nm}$ and $D \approx 3 \times 10^{-16}$ $\mathrm{cm}^{2} / \mathrm{s}$. The derived diffusion coefficient under irradiation in ferrite is significantly greater than the thermal diffusivity ( $D \approx 10^{-19} \mathrm{~cm}^{2} / \mathrm{s}$ ) of Fe-Cr alloys [30]. Furthermore, an estimated diffusion distance of $\sim 9 \mathrm{~nm}$ implies that the effect of the free surface can be neglected in the APT measurement considering that the surface measured by APT was $\sim 120 \mathrm{~nm}$ away from the ion-irradiated surface (see Fig. 5). 
The sink strength in the aged and ion-irradiated CF8 can also be estimated. According to Russell [20], the radiation-enhanced diffusion coefficient is dominated by the fixed defect sink strength at intermediate temperature range, i.e.:

$$
D \approx \frac{2 K}{k_{i}^{2}},
$$

where $K$ is the atomic displacement rate, and $k_{i}$ is the fix sink strength for interstitials. The sink strength estimated for the aged and irradiated CF8 is approximately $7 \times 10^{16} / \mathrm{m}^{2}$, which is comparable to the sink strength of oxide-dispersion-strengthened (ODS) steels reported in the literature [31].

Phase separation of Fe-rich $\alpha$ phase and Cr-enriched $\alpha^{\prime}$ phase by spinodal decomposition in the ferrite was revealed by APT in the thermally-aged CF8. When irradiated with $1 \mathrm{MeV} \mathrm{Kr}$ ions at $400^{\circ} \mathrm{C}$, the peak $\mathrm{Cr}$ concentration in $\alpha^{\prime}$ phase ( $\left.\mu 2\right)$ decreased with increasing dose, implying that there was a tendency that phase separation was diminished under irradiation. This observation is consistent with the findings reported by Fujii and Fukuya [19] that irradiation reduced spinodal decomposition in an aged CF8M steel irradiated with $6.4 \mathrm{MeV}$ Fe ions to 1 dpa at $300^{\circ} \mathrm{C}$. However, Miller et al [17] observed enhanced spinodal decomposition in an $\mathrm{Fe}-32 \% \mathrm{Cr}$ alloy neutron irradiated at $290^{\circ} \mathrm{C}$. It should be noted that there are large variations between these three experiments in terms of irradiation dose rate, chemistry of the material, etc. Irradiation causes strong atomic mixing, and this disordering could inhibit the tendency of spinodal decomposition. In the meanwhile, irradiation enhances diffusion which can accelerate phase separation. These two micro-processes have opposite effects on microstructural evolution. The resulting irradiation microstructures are determined essentially by the balance of these processes during irradiations. Miller et al. [17] suggested that the enhanced spinodal decomposition in the 
neutron-irradiated Fe-32\%Cr alloy may be explained by the neutron irradiation induced changes in the location of the phase field in the phase diagram. While further analysis is being conducted to fully understand the effect of irradiation on spinodal decomposition in CF8, large variations in irradiation dose rate may contribute to the apparent conflicting effect on spinodal decomposition observed in neutron-irradiated Fe-32\%Cr model alloys and ion-irradiated CASS CF8 and CF8M.

The implantation of $\mathrm{Kr}$ ions in the ion-irradiated CF8 specimen provided an effective means for the estimation of the irradiation dose profile in the APT specimen, as illustrated in Fig. 5. The effect of implantation of heavy inert gases, e.g. Kr, Ar, Xe on irradiation-induced microstructural changes has been addressed extensively in the literature [32]. Due to the insolubility of inert gases in metals, heavy inert gases can precipitate in bubbles, which can be in the solid form at room temperature involving the high pressure, e.g. $\mathrm{Kr}$ bubbles in $\mathrm{Cu}, \mathrm{Ni}$ and $\mathrm{Au}$ [33]. The influence of $\mathrm{Kr}$ implantation on G-phase and $\alpha$ ' phase formation is expected to be insignificant.

\section{CONCLUSIONS}

APT analysis revealed the formation of nanometer-sized G-phase precipitates and phase separation of Fe-rich $\alpha$ and Cr-rich $\alpha^{\prime}$ phases in the ferrite phase in a CF8 that was thermallyaged at $400{ }^{\circ} \mathrm{C}$ for $10,000 \mathrm{~h}$. When the thermally-aged CF8 was subjected to the $400{ }^{\circ} \mathrm{C}$ irradiation with $1 \mathrm{MeV} \mathrm{Kr}$ ions, the number density of the G-phase precipitates increased and the mean size decreased with increasing dose. Irradiation also changed the size distribution of Gphase precipitates considerably, from a binominal distribution with the peak size of $4.8 \mathrm{~nm}$ in the unirradiated state to a bimodal distribution after 1-3 dpa, and back to a binominal distribution with a smaller peak size at $>3 \mathrm{dpa}$. This inverse coarsening process can be described by recoil 
resolution. Phase separation of Fe-rich $\alpha$ and Cr-enriched $\alpha^{\prime}$ phases in the ferrite was apparently reduced after heavy ion irradiation.

\section{ACKNOWLEDGEMENT}

The ion irradiation was accomplished at Argonne National Laboratory at the IVEMTandem Facility, a user facility funded by the US Department of Energy Office of Nuclear Energy, operated under Contract No. DE-AC02-06CH11357 by UChicago Argonne, LLC. Atom probe tomography was conducted at the Center for Nanophase Materials Sciences, which is a DOE Office of Science User Facility. Marquis A. Kirk and Pete Baldo are thanked for assisting ion irradiation experiments at the Argonne's IVEM-Tandem Facility. Yiren Chen at ANL is thanked for providing the materials, helpful discussion, and conducting the paper review.

\section{REFERENCES}

1. Chopra, O. K., and A. Sather, "Initial Assessment of the Mechanisms and Significance of Low-Temperature Embrittlement of Cast Stainless Steels in LWR Systems," NUREG/CR5385, ANL-89/17, 1990.

2. Andresen, P. L., F. P. Ford, K. Gott, R. L. Jones, P. M. Scott, T. Shoji, R. W. Staehle, and R. L. Tapping, "Expert Panel Report on Proactive Materials Degradation Assessment (PMDA)," NUREG/CR-6923, BNL-NUREG-77111-2006, 2007.

3. Nichol, T. J., A. Datta, and G. Aggen, Metall. \& Mater. Trans. A 11 (1980) 573.

4. Trautwein, A., and W. Gysel, ASTM STP 756 (1982) 165.

5. Y. Chen, B. Alexandreanu, K. Natesan, and A. S. Rao, "Cracking of Irradiated Cast Stainless Steels in Low Corrosion Potential Environments," $16^{\text {th }}$ Inter. Conf. on Environmental Degradation of Materials in Nuclear Power Systems - Water Reactors, August 11-15, 2013, Asheville, NC.

6. Fisher, R. M, E. J. Dulis, and K. G. Carroll, Trans. AIME, 197 (1953) 690.

7. Grobner, P. J., "The $885^{\circ} \mathrm{F}\left(475^{\circ} \mathrm{C}\right)$ Embrittlement of Ferritic Stainless Steels," Metallurgical and Materials Transactions B, 4, No. 1 (1973): 251-260.Hiser, A. L., "Tensile and J-R Curve Characterization of Thermally Aged Cast Stainless Steels,” NUREG/CR-5024, MEA-2229, 1988. 
8. Solomon, H. D., and T. M. Devine, ASTM STP 672 (1979) 430.

9. Chung, H. M., and O. K. Chopra, "Kinetics and Mechanism of Thermal Aging Embrittlement of Duplex Stainless Steels," Proc. 3rd Intl. Symp. on Environmental Degradation of Materials in Nuclear Power Systems -- Water Reactors, Metallurgical Society, 1987.

10. Chung, H. M., and T. R. Leax, Mater. Sci. \& Tech. 6 (1990) 249.

11. Leax, T. R., S. S. Brenner, and J. A. Spitznagel, Metall. \& Mater. Trans. A, 23 (1992) 2725.

12. Hamaoka, T., A. Nomoto, K. Nishida, K. Dohi, and N. Soneda, Phil. Mag. 92 (2012) 2716.

13. J.M Vitek, S.A. David, D.J. Alexander, J.R. Keiser, R.K. Nanstad, Acta Metall. Mater. 39 (1991) 503.

14. K.B. Alexander, M.K. Miller, D.J. Alexander and R.K. Nanstad, Master. Sci. Tech. 6 (1990) 314.

15. S.A. David, J.M. Vitek, J.R. Keiser and W.C. Oliver, Weld. J. 66 (1987) 235s.

16. G.E. Hale, J.R. Gordon and B. Hemsworth, in Environmental Degradation of Materials in Nuclear Power Systems - Water Reactors (edited by G. J. Theus and J.R. Weeks), pp. 723730. T.M.S. -A.I.M.E., Warrendale, Pa (1998).

17. M.K. Miller, R.E. Stoller and K.F. Russell. J. Nucl. Mater. 230 (1996) 219.

18. S.J. Zinkle, Radiation-Induced Effects on Microstructure. In: Konings R.J.M., (ed.) Comprehensive Nuclear Materials 1 (2012) 65.

19. K. Fujii and K. Fukuya, J. Nucl. Mater. 440 (2013) 612.

20. K.C. Russell, Prog. Mater. Sci. 28 (1984) 229.

21. M. K. Miller, R.G. Forbes, Atom Probe Tomography: The Local Electrode Atom Probe, Springer, New York, 2014.

22. W. Chen et al. (to be published).

23. J.F. Ziegler, J.P. Biersack, M.D. Ziegler, SRIM: The Stopping and Range of Ions in Matter, 2012.

24. M. K. Miller, K. F. Russell, K. Thompson, R. Alvis and D. J. Larson, Microscopy and Microanalysis, 13(6) (2007) 428.

25. K. Thompson, D. Lawrence, D.J. Larson, J.D. Olson, T.F. Kelly and B. Gorman, Ultramicroscopy, 107 (2007) 131.

26. D. J. Larson, T. J. Prosa, R. M. Ulfig, B. P. Geiser and T. F. Kelly, Local Electrode Atom Probe Tomography, Springer, New York, 2013.

27. M. G. Hetherington, J. M. Hyde, M. K. Miller, and G. D. W. Smith, Surf. Sci., 246 (1991) 304.

28. J.S. Langer, M. Bar-on and H.D. Miller, Phy. Rev. A 11 (1975) 1417.

29. H.J. Frost and K.C. Russell, J. Nucl. Mater. 103\&104 (1981) 1427.

30. B. Jonsson, ISIJ Inter. 35 (1995) 1415.

31. S.J. Zinkle and L.L. Snead, Annu. Rev. Mater. Res. 44 (2014) 241.

32. S.E. Donnelly and J.H. Evans, Fundamental Aspects of Inert Gases in Solids, Springer Science \& Business Media, Series: Nato Science Series B: v. 279 (1991).

33. J.H. Evans and D.J. Mazey, J. Phys. F: Met. Phys. 15 (1985) L1. 


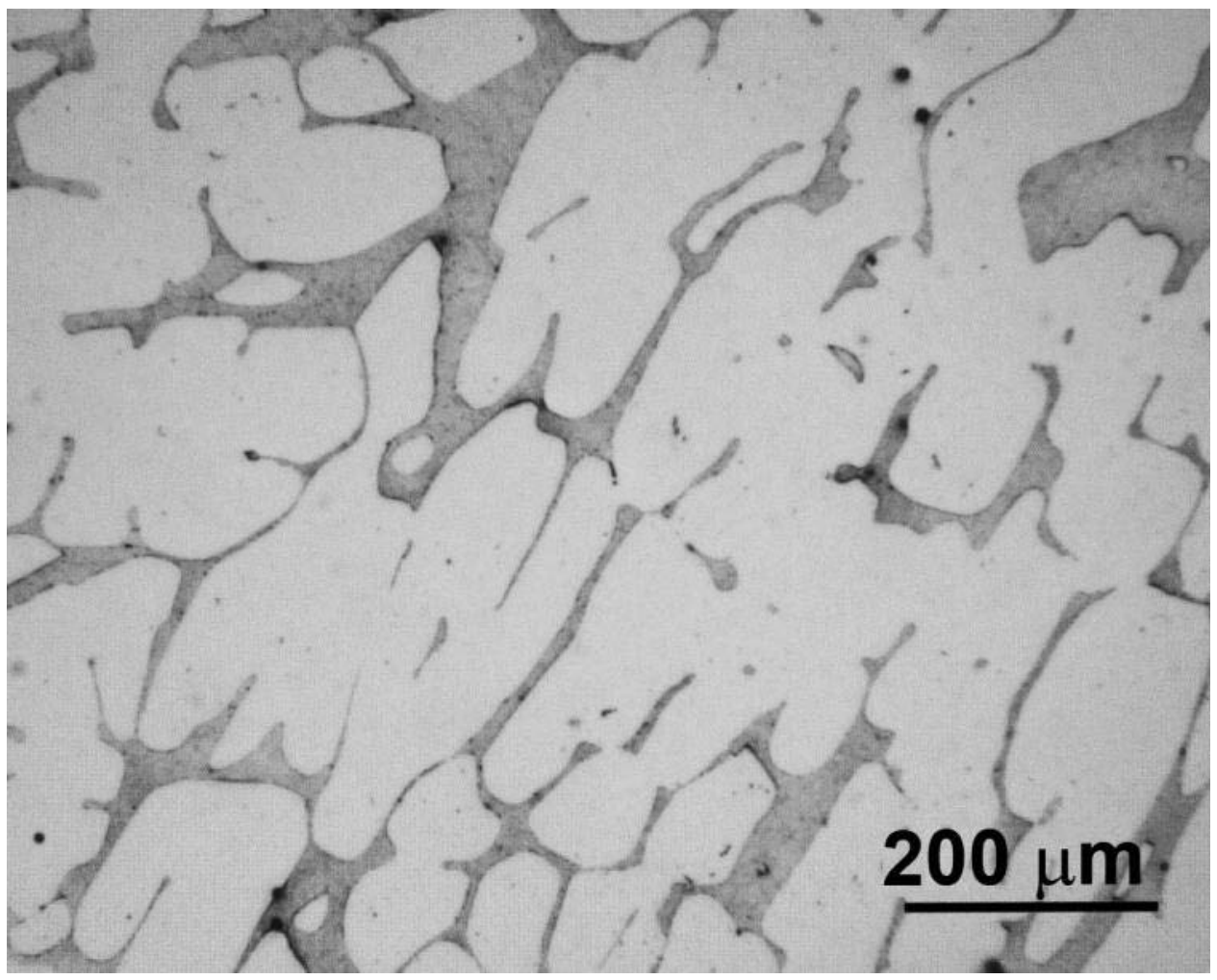

Figure 1. Optical micrograph showing the ferrite (dark grey) - austenite (light grey) duplex structure in CF8 steel. 


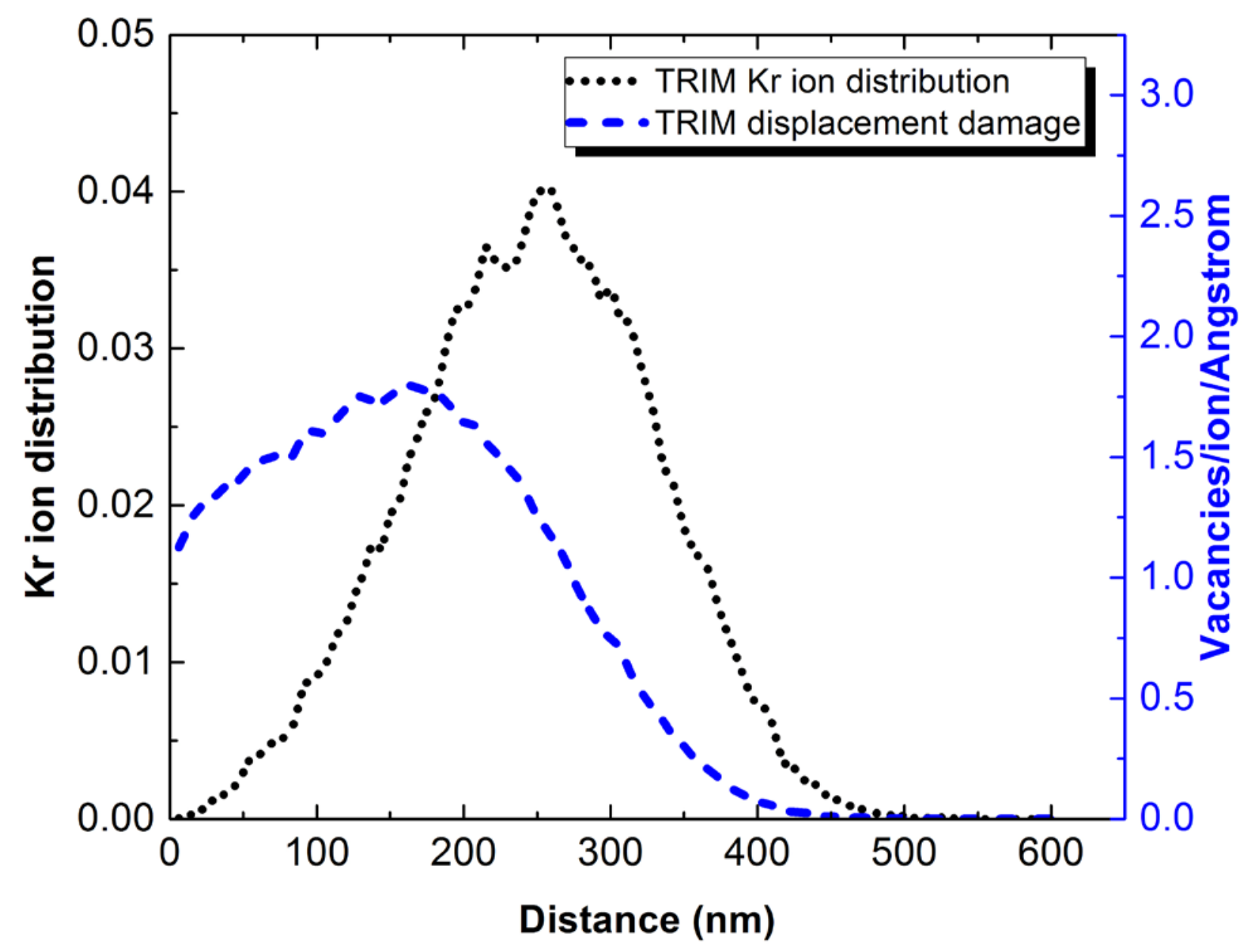

Figure 2. TRIM calculations of the displacement damage and $\mathrm{Kr}$ ion distributions through the specimen thickness in pure iron irradiated with $1 \mathrm{MeV} \mathrm{Kr}$ ions. 


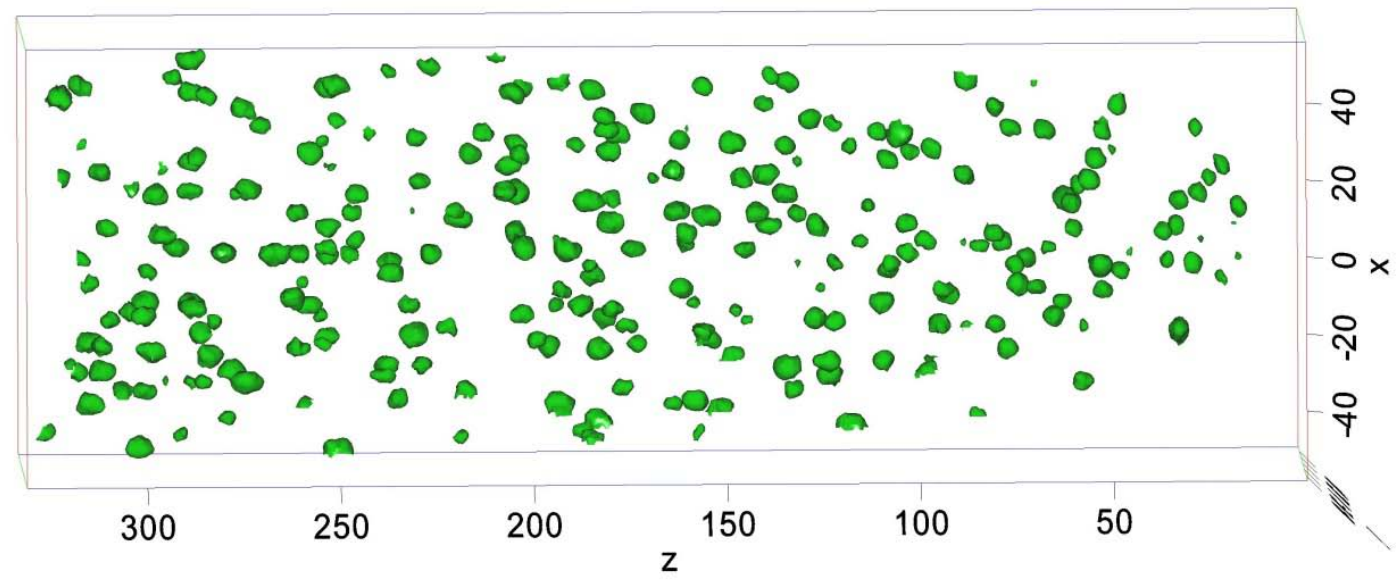

(a)

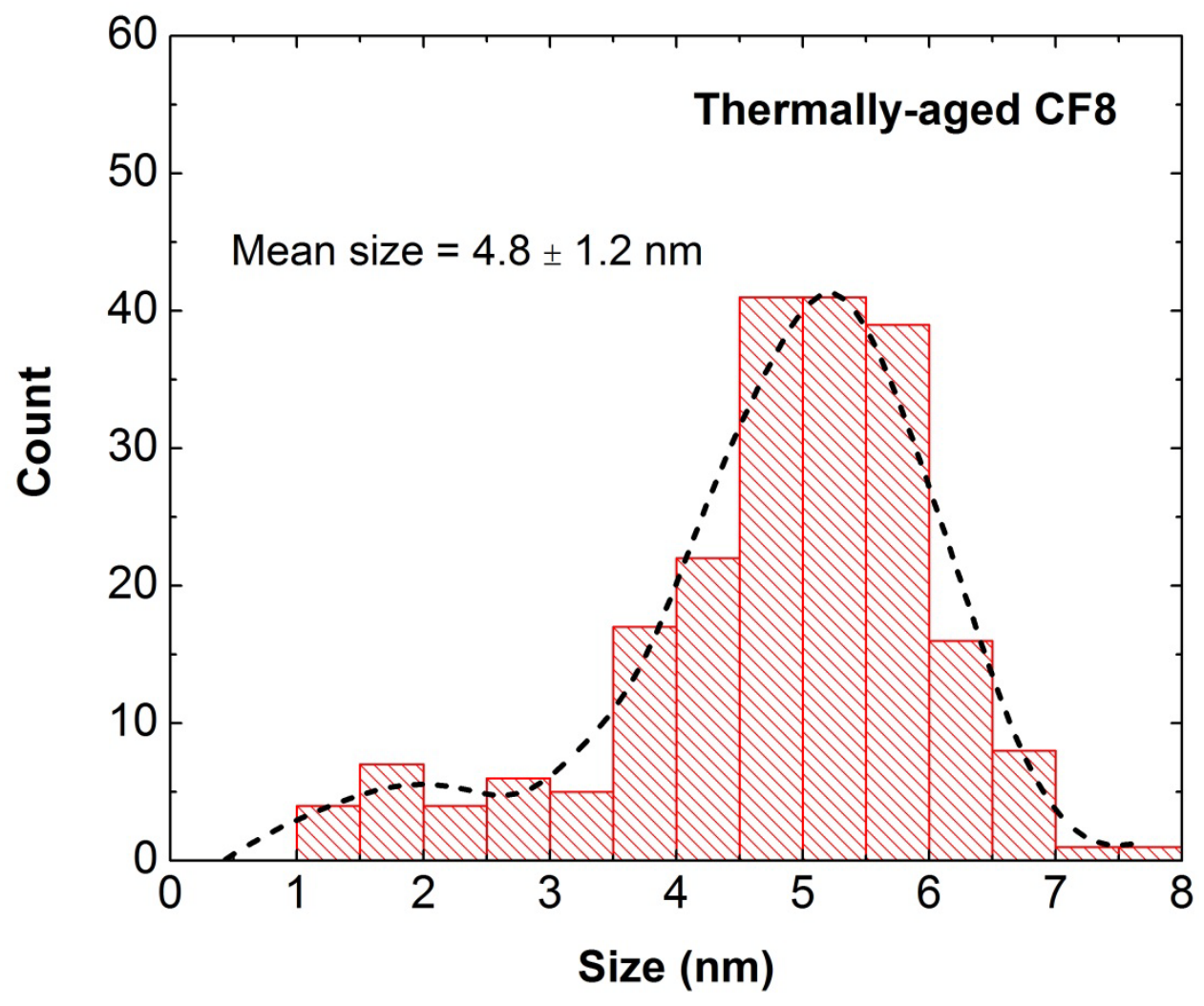

(b)

Figure 3. (a) The 10 at. \% $\mathrm{Ni}+\mathrm{Si}$ concentration isosurface and (b) size distribution of G-phase precipitates in ferrite in the CF8 specimen aged at $400^{\circ} \mathrm{C}$ for $10,000 \mathrm{~h}$. 


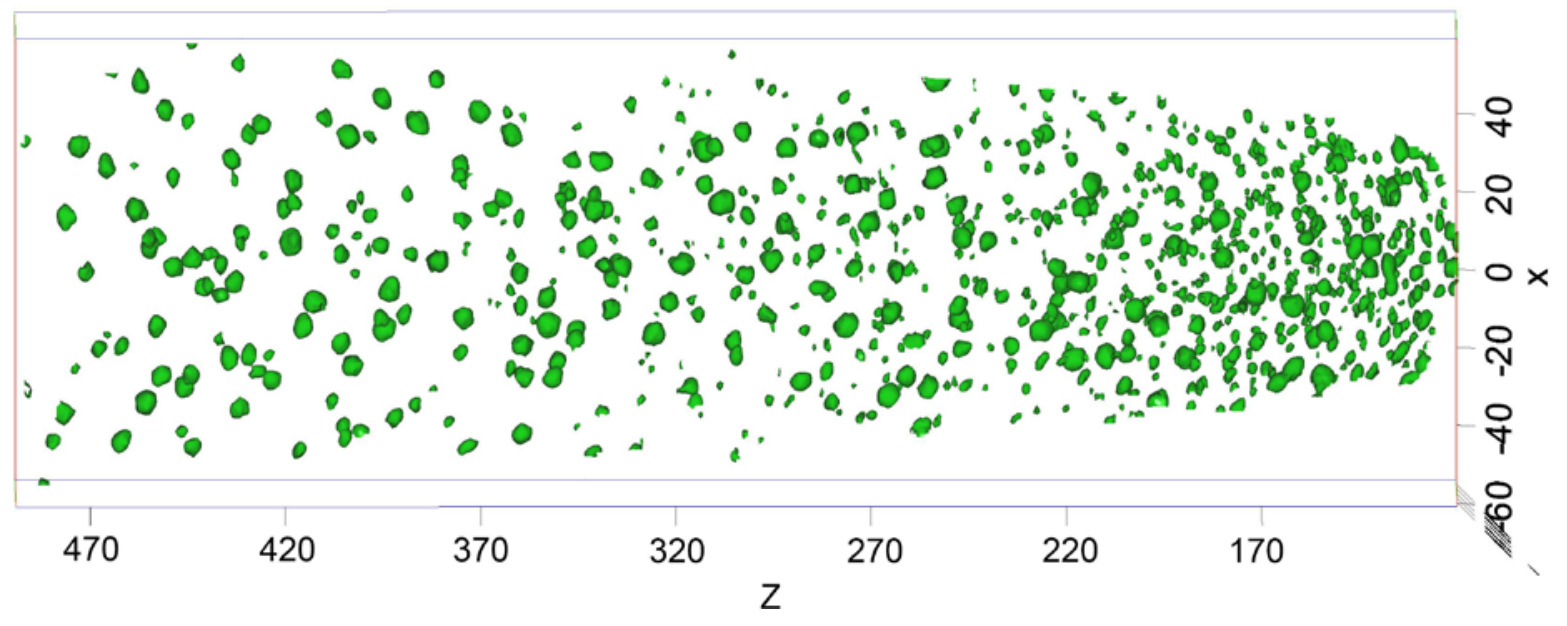

Figure 4. The 10 at. \% Ni+Si concentration isosurface for the aged CF8 specimen irradiated to $1.88 \times 10^{19} \mathrm{ions} / \mathrm{m}^{2}$ at $400^{\circ} \mathrm{C}$. 


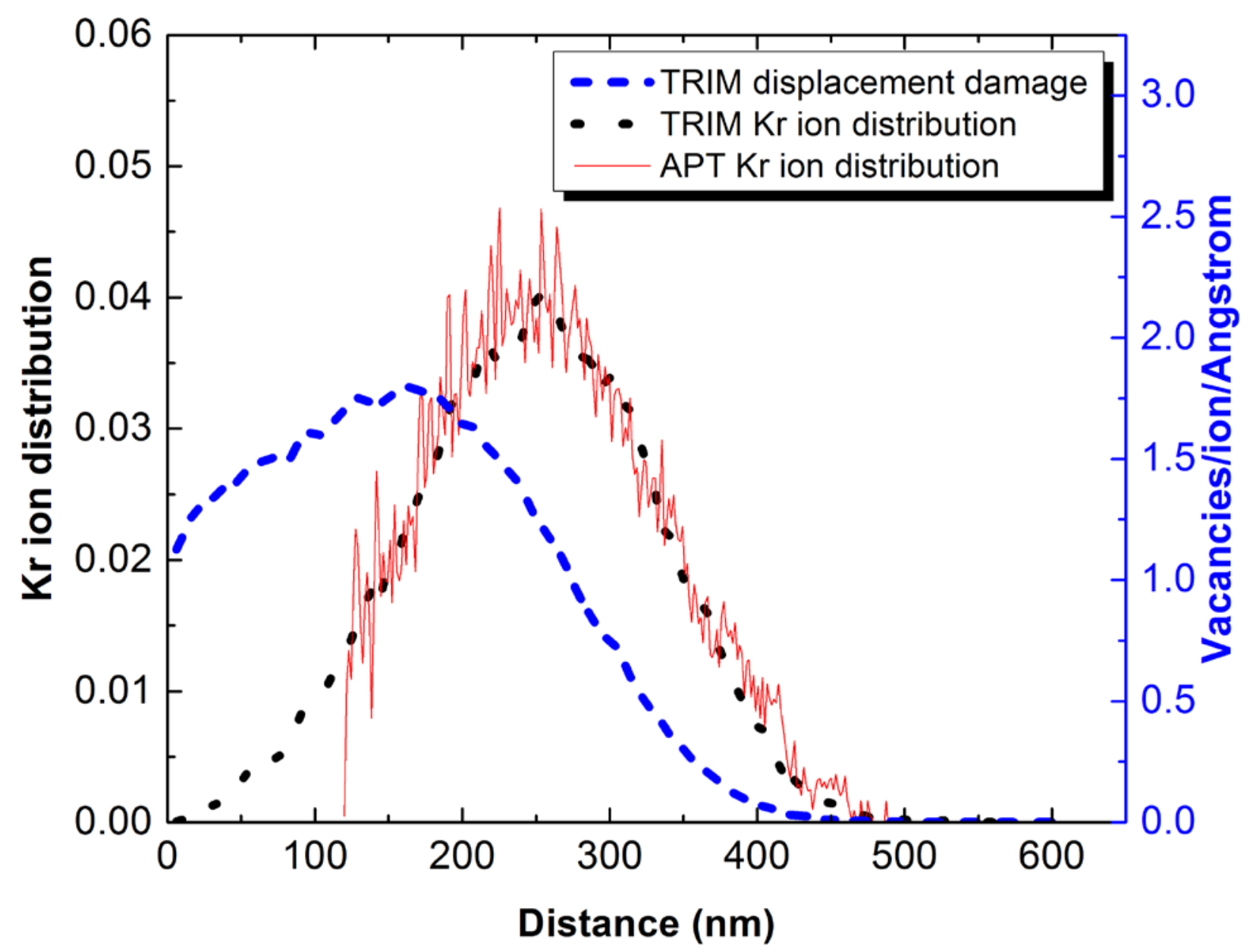

Figure 5. Comparison of $\mathrm{Kr}$ ion distributions calculated by TRIM and measured by APT to determine the distance of the surface measured by APT from the ion-irradiated surface for the thermally aged CF8 specimen irradiated to $1.88 \times 10^{19}$ ions $/ \mathrm{m}^{2}$ at $400^{\circ} \mathrm{C}$. 


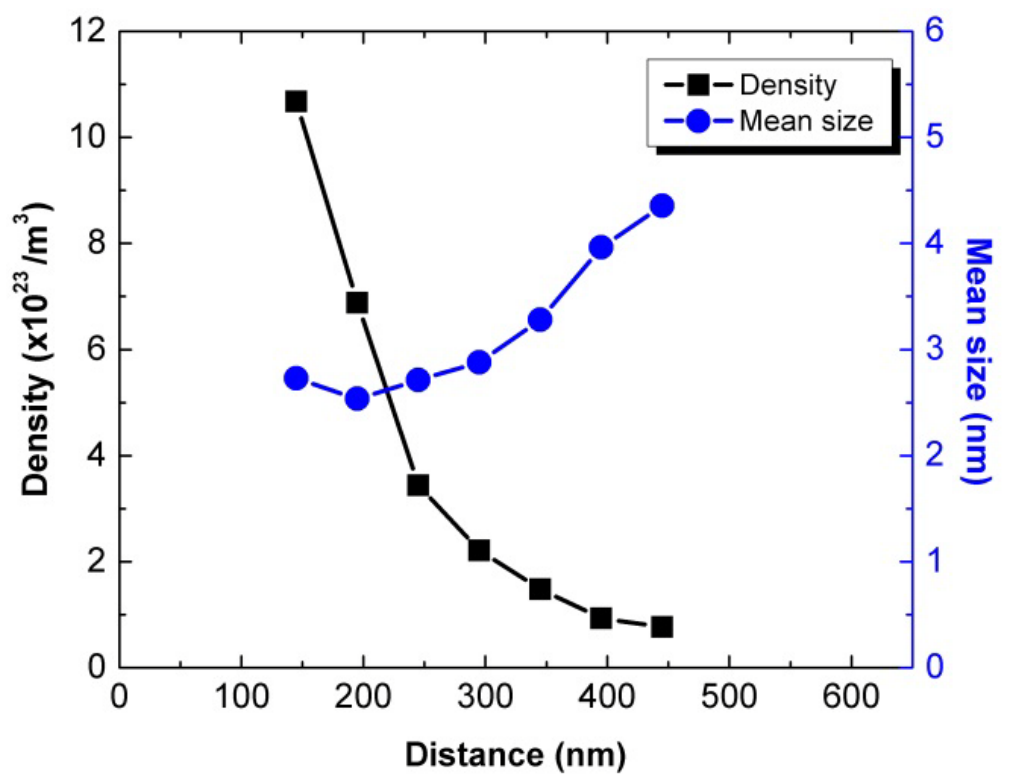

(a)

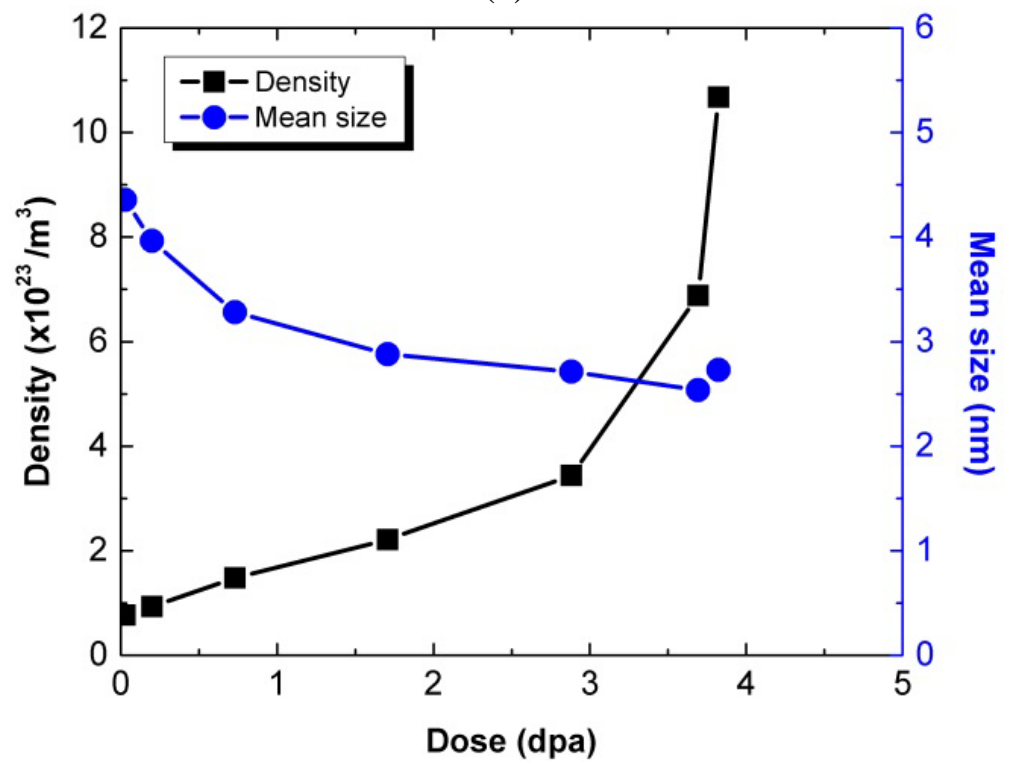

(b)

Figure 6. Number density and mean size of the G-phase precipitates as a function of the distance from the ion irradiation surface (a) and corresponding irradiation dose (b) for the aged CF8 specimen irradiated to $1.88 \times 10^{19}$ ions $/ \mathrm{m}^{2}$ at $400^{\circ} \mathrm{C}$. 


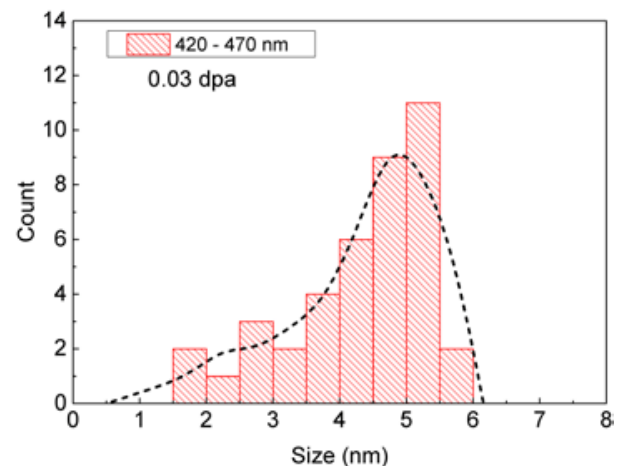

(a)

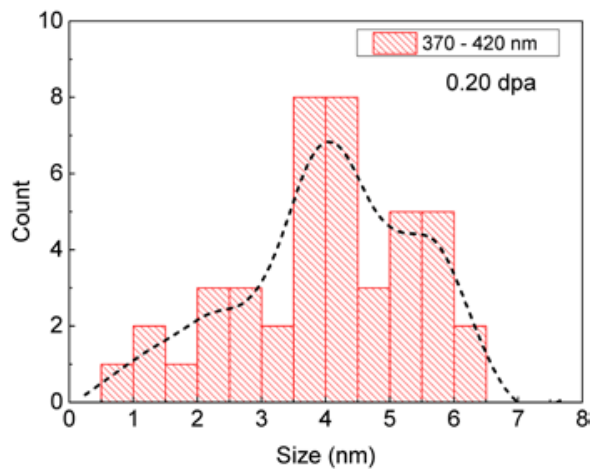

(b)
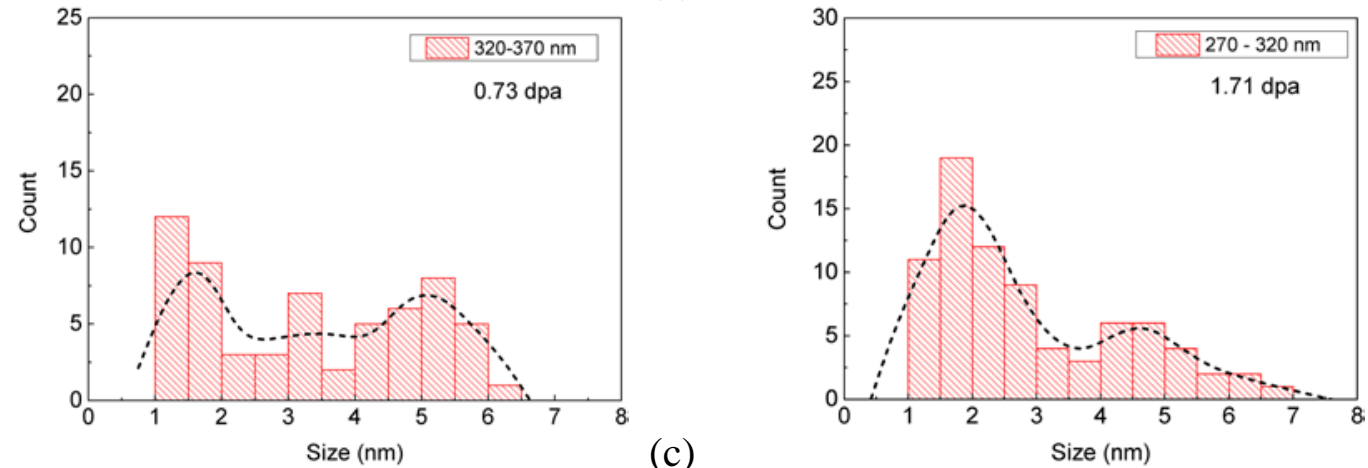

(d)

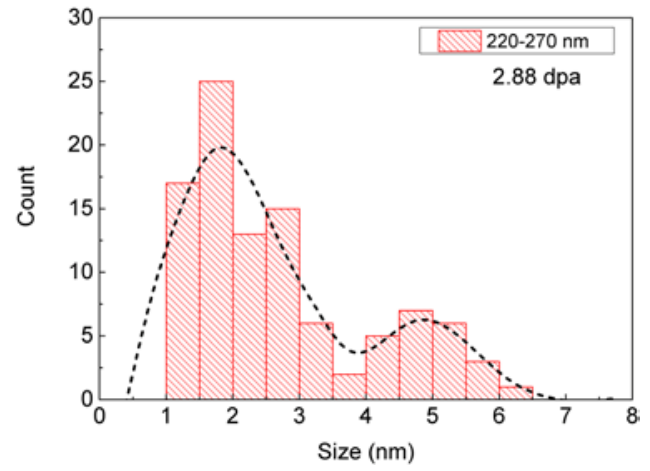

(c)
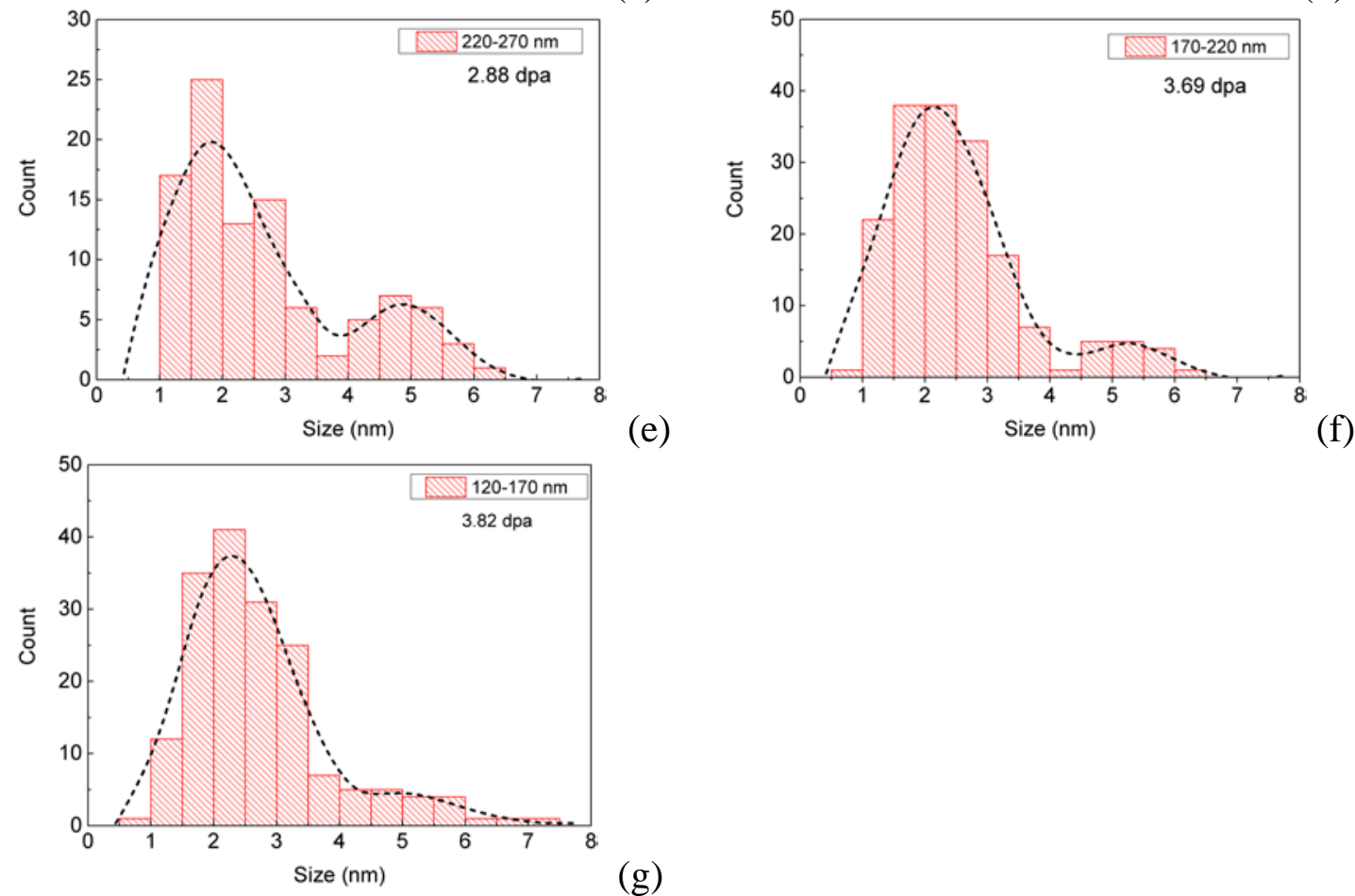

(e)

Figure 7. Size distributions of the G-phase precipitates in the thermally aged CF8 specimen irradiated to $1.88 \times 10^{19}$ ions $/ \mathrm{m}^{2}$ at $400^{\circ} \mathrm{C}$. The distance values are consistent with those in Fig. 4 . 


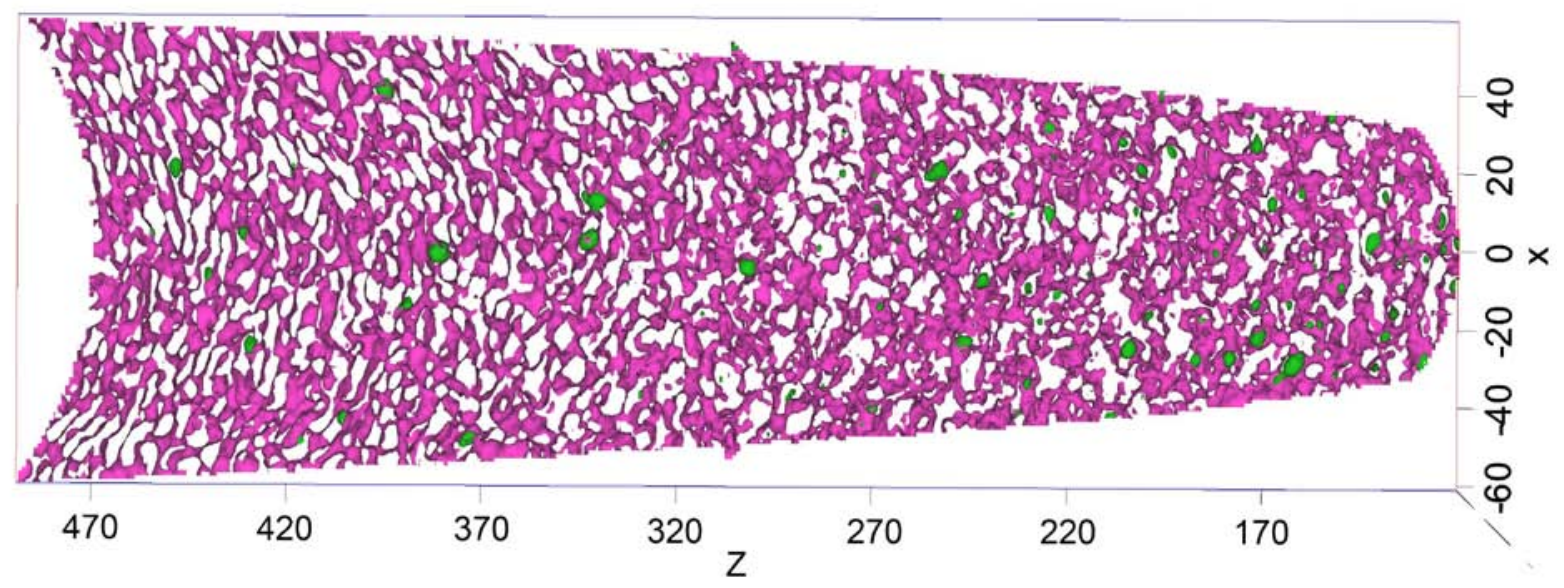

Figure 8 . The 15 at \% Cr (Purple) 10 at. \% Ni+Si (Green) concentration isosurface for the aged CF8 specimen irradiated to $1.88 \times 10^{19}$ ions $/ \mathrm{m}^{2}$ at $400^{\circ} \mathrm{C}$. 


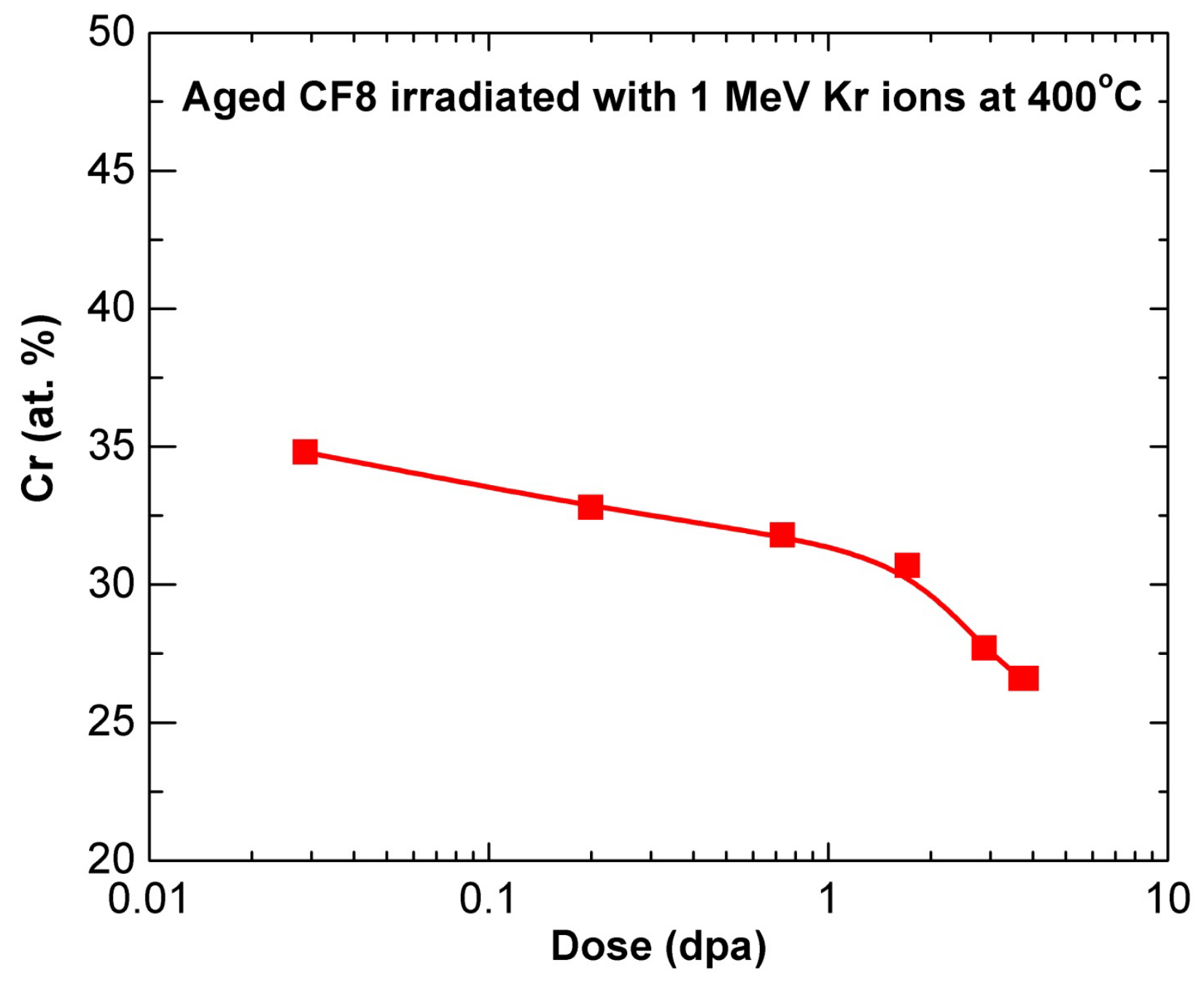

Figure 9. The $\mu 2$ value of the $\alpha^{\prime}$ phase in the LBM analysis as a function of distance/dose along the analysis axis for the thermally aged CF8 irradiated to $1.88 \times 10^{19} \mathrm{ions} / \mathrm{m}^{2}$ at $400^{\circ} \mathrm{C}$. 


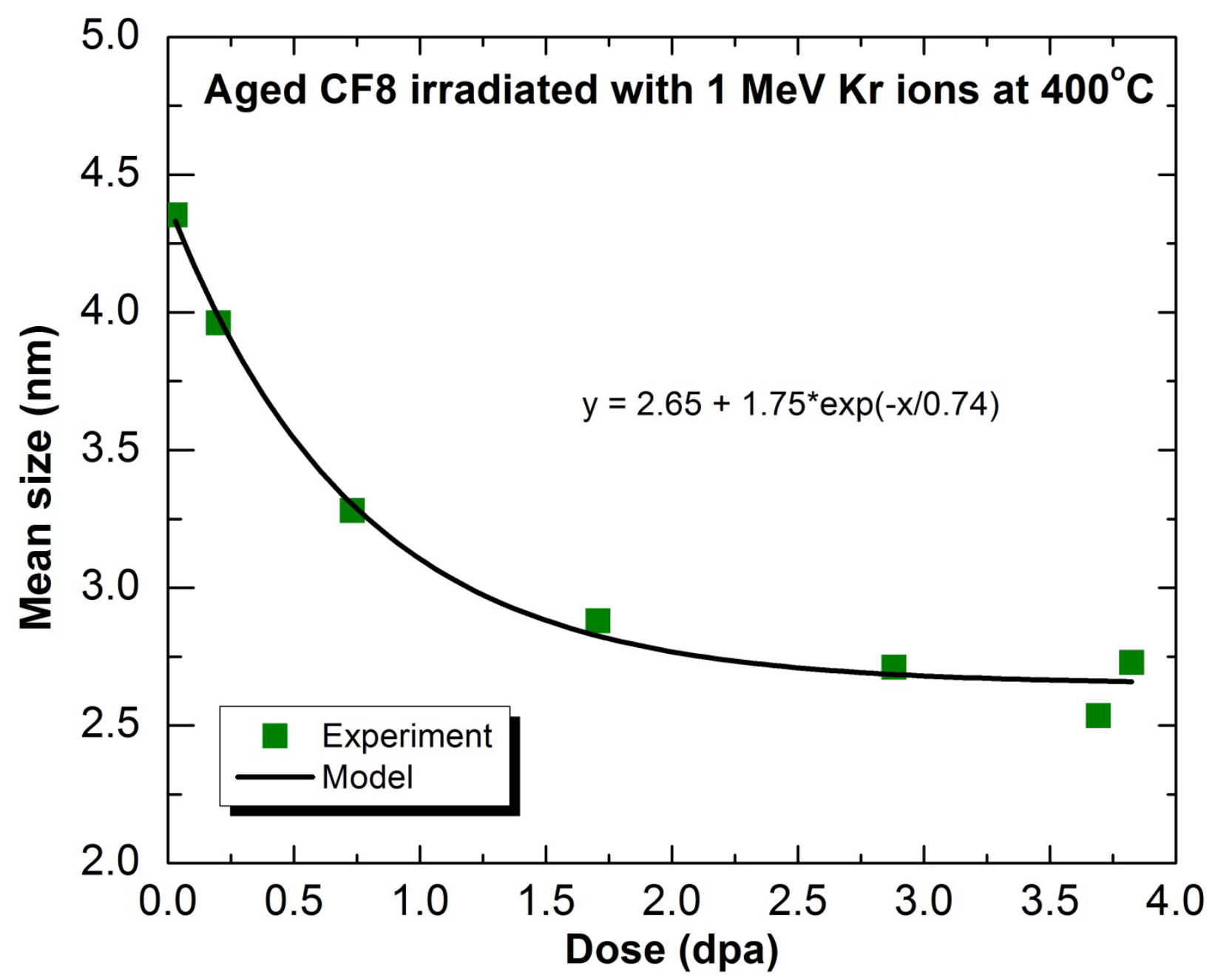

Figure 10. Comparison of experiment and modeling of the mean size of G-phase precipitates as a function of dose in the thermally-aged CF8. 